Session 1330

\title{
How Chemical Engineering Seniors Think about Mechanisms of Momentum Transport
}

\author{
Ronald L. Miller, Ruth A. Streveler, Barbara M. Olds \\ Colorado School of Mines
}

\section{Introduction}

Faculty members who teach courses in transport sciences often observe that even students who can correctly solve problems in fluid dynamics, heat and mass transfer, or thermodynamics still believe that "processes stop when they reach equilibrium." These faculty observations are supported by literature suggesting that science and engineering students do not conceptually understand many fundamental molecular-level and atomic-level phenomena including heat, light, diffusion, chemical reactions, and electricity. [1,2] The problem is more than simply one of confusion or misunderstanding, but instead involves fundamental misconceptions by students about differences in the way that molecular-scale processes differ from observable, macroscopic causal behavior we experience in our daily lives. [3]

Engineering instructors find that molecular-scale phenomena such as viscous fluid flow, conductive heat transfer, diffusional mass transfer, and thermodynamic equilibrium are very difficult for students to learn and, even after instruction, students persist in their misconceptions. For example, engineering students often describe molecular momentum transfer as faster molecules "dragging slow molecules along," heat as a "substance stored in hot objects" as opposed to cold which is described as a "substance stored in cold objects," heat transfer as a "flow of hot molecules to cold objects," and molecular processes as "stopping" when they reach equilibrium. None of these conceptually flawed explanations is correct and each leads to incorrect explanations of other related phenomena (for example, incorrectly predicting the absence of a temperature effect on equilibrium processes or predicting that no molecular diffusion occurs in laminar fluid flow).

Why are these concepts so difficult for students to learn? Part of the reason seems to be that certain beliefs are very entrenched and not easily changed. [4] Based largely on life experience, these beliefs are formed early in a student's career (perhaps even before the start of formal schooling) and become the basis for future learning via the construction of increasingly complicated mental models. [5] If the student's prior knowledge is incomplete or incorrect, new concepts are difficult if not impossible to correctly assimilate and a fundamental conceptual change in the student's mental model will be required before the new concept can be understood.

For many traditional processes, the macroscopic models and metaphors ("heat flows") still work well and students must still be proficient in their use. However, given the increasing number of engineering systems that explicitly rely upon molecular-level phenomena (e.g. biotechnology, microelectronics, molecular computers, and many others), we argue that students must also 
understand when macroscopic and microscopic models will break down and when the metaphors are no longer applicable.

Electricity, fluid flow, heat transfer and molecular equilibrium are examples of emergent processes (processes that involve uniform, parallel, independent events with no beginning or end but in which observable patterns eventually emerge). Chi has proposed that conceptual misunderstandings arise when students incorrectly think of emergent processes as having the attributes of the causal processes they see in everyday life. [6] (Causal processes involve distinct, sequential, goal-oriented events that have an observable beginning and end). Therefore, students may view the observed structure or patterns emerging from a series of events such as Brownian molecular motion (the result of an emergent process) as actually being the result of a causal process. They often incorrectly describe molecules as moving with intent in a linear and sequential process that stops at some point. Thus, Chi's theory explains why students persist in their belief that molecules move with intent and that heat is a substance that flows and can be stored. [1] There is also evidence in the literature that causal explanations are often incorrectly invoked as metaphors in textbooks and by faculty members. [1,7] Although the metaphors can be useful, students do not know when relying on the metaphor is appropriate and when it must be abandoned for a more realistic conceptual explanation of a process.

Table 1 provides a detailed example (diffusion of colored dye in a beaker of water) about how students incorrectly classify most processes in which structure or pattern emerges from a series of separate events as a causal process involving directed action of individual objects with a defined beginning and end. Marek and colleagues have shown that less than $2 \%$ of high school students correctly understand diffusion after completing a biology or chemistry course. [8] We would expect similar numbers for college engineering and science students based on research by Hestenes that misconceptions developed in elementary and secondary schools persist into college. [9]

Consider the simple experiment of adding a droplet of colored dye into a beaker of quiescent water. What we see at the macroscopic level is slow movement (diffusion) of dye into the water until the resulting dye/water mixture has the same color throughout the beaker. At this point (equilibrium) no further movement of dye is apparent to the naked eye. As shown in the left column of Table 1, this experiment can be (incorrectly) described using a causal model in which dye molecules "want" to mix with water and individual dye molecules move with intent to create a uniform dye/water mixture at which time they stop further movement. (What really happens is that dye and water molecules will randomly bounce into spaces formerly occupied by other dye and water molecules eventually resulting in a uniform mixture in which both types of molecules continue to move. The initial concentration difference between dye and water means that on average more of the dye molecules will initially move into regions populated by water molecules). Students who describe this complex, dynamic process using the causal explanation possess a mental model that is fundamentally incommensurate with accepted theories of molecular motion. Since the causal model seems to describe the macroscopic behavior of the dye/water experiment, students are comfortable with this view (as are many faculty members as evidenced by typical textbook descriptions of this process) and they hold tightly to the misconception, especially that the dye molecules stop moving once equilibrium is reached. This approach provides students with simple equations for describing the rates of diffusional 
processes (i.e. Fick's law of diffusion in mixtures, Fourier's law of heat conduction, Newton's law of viscosity for momentum transfer) and allows them to predict the macroscopic behavior of simple diffusional systems.

Table 1. Comparison of Causal vs. Emergent Processes Explanation for Diffusion of Colored Dye in Water $[6,10]$

\begin{tabular}{|c|c|}
\hline $\begin{array}{c}\text { Causal Model } \\
\text { (the action of a class of molecules) }\end{array}$ & $\begin{array}{c}\text { Emergent Model } \\
\text { (interactions of a dynamic collection of molecules) }\end{array}$ \\
\hline $\begin{array}{l}\text { "Dye molecules move towards water molecules." } \\
\text { (distinct actions - event is composed of distinct } \\
\text { subevents) }\end{array}$ & $\begin{array}{l}\text { "All molecules exercise Brownian motion." } \\
\text { (uniform interactions - interactions follow the same } \\
\text { rules for all members of the collection) }\end{array}$ \\
\hline $\begin{array}{l}\text { "Dye molecules flow from area of high } \\
\text { concentration to area of low concentration." } \\
\text { (sequential actions - subevents happen in a } \\
\text { particular order) }\end{array}$ & $\begin{array}{l}\text { "All molecules move at the same time." } \\
\text { (simultaneous interactions - interactions among } \\
\text { members occur simultaneously) }\end{array}$ \\
\hline $\begin{array}{l}\text { "Dye molecules are "pushed" into the water by } \\
\text { other dye molecules." } \\
\text { (dependent actions - a subevent is dependent on the } \\
\text { event that came before it) }\end{array}$ & $\begin{array}{l}\text { "Molecules collide independently of prior } \\
\text { collisions. What happens to one molecule doesn't } \\
\text { affect interactions of other molecules." } \\
\text { (independent interactions - each member collision } \\
\text { occurs independently of others) }\end{array}$ \\
\hline $\begin{array}{l}\text { "Dye molecules want to mix with water } \\
\text { molecules." } \\
\text { (goal-direct actions - actions are taken to achieve a } \\
\text { goal) }\end{array}$ & $\begin{array}{l}\text { "The local conditions around each molecule affect } \\
\text { where it moves and at what velocity." } \\
\text { (local and decentralized interactions - interaction } \\
\text { determined by local conditions) }\end{array}$ \\
\hline $\begin{array}{l}\text { "Dye molecules stop moving when dye and water } \\
\text { become mixed." } \\
\text { (termination - action stops when goal is achieved) }\end{array}$ & $\begin{array}{l}\text { "Molecular interactions continue when equilibrium } \\
\text { is reached." } \\
\text { (continuous interactions - interactions continue } \\
\text { irrespective of what is observable at the macro } \\
\text { level) }\end{array}$ \\
\hline
\end{tabular}

In addition to the causal (macroscopic) and emergent (molecular) models, students are often presented with microscopic models to explain emergent phenomena. An example of a microscopic model would be describing laminar fluid flow as layers of fluid moving past one another. Microscopic models may be thought of as a way of "macro-tizing" the emergent phenomena to make them more understandable. Microscopic models attempt to examine phenomena on a smaller scale than the macroscopic models, but still do not use the properties of emergent phenomena to describe what is truly happening at the molecular level.

If the macroscopic and microscopic models are successful in describing the global behavior of simple systems, why should we care if students persist in incorrectly applying causal models to processes such as dye diffusion into water? The answer is simple - the causal models can predict some but not all important behavioral characteristics of molecular diffusional processes. For example, students will not be able to predict the effect of changing the initial amount of dye or the effect of temperature on diffusion rates using a causal model. Given the increasing importance of dynamic molecular behavior in many fields of engineering and science, we believe identifying persistent student misconceptions about important concepts in thermal and transport 
sciences is an important step towards improving the quality of student learning in these disciplines.

\section{Procedure}

In this study, we investigate the kinds of models chemical engineering seniors use to describe one particular transport phenomenon. On the first day of a senior-level transport phenomena course, the 39 chemical engineering students enrolled in the course were asked to answer the question:

"Explain in your own words (no equations) how momentum is transferred through a fluid via viscous action."

We posed two research questions when analyzing student responses to this question:

1. Do students use words in their descriptions that suggest they are using causal models?

2. What models (macroscopic, microscopic, molecular, or a mixture of these three) do students use to explain this phenomenon?

In order to investigate whether students used descriptions relating to causal or emergent processes (question 1), we created a list of terms that related to each process using the descriptions in Table 1 as a guide. The raters then used these lists to look for evidence in the student descriptions that indicated students were using causal models. For example, phrases such as "fluid particles grabbing hold of other fluid particles" and "fluid particles experiencing a shear stress" indicated causal thinking while phrases like "molecules colliding and transferring energy" and "random intermolecular interactions in the fluid" indicated emergent thinking.

To answer question 2, we created sample descriptions of viscous momentum transport using macroscopic, microscopic, and molecular mental models. These descriptions are listed in Table 2 and were used as a rubric to score student responses. Some students used a combination of models in their descriptions which were labeled as "mixed" models in our scoring. A few students also gave answers so vague that they could not be scored. These are listed as "nonresponsive."

\section{Results}

Copies of student responses were distributed to three coders. At least two coders had to agree with their categorization for a code to be considered valid. If coders disagreed, discussion ensued until agreement was reached. Results are summarized in Tables 3 and 4. 
Table 2. Macroscopic, Microscopic, Molecular, and Mixed Descriptions of Viscous Momentum Transfer in Laminar Pipe Flow Used as Scoring Rubric for Student Responses

\section{Macroscopic Description}

The pressure at the pipe inlet is increased (usually by pumping) which causes the fluid to move through the pipe. Friction between fluid and pipe wall results in a pressure drop in the direction of flow along the pipe length. The fluid at the wall does not move (no-slip condition) while fluid furthest away from the wall (at the pipe centerline) flows the fastest, so momentum is transferred from the center (high velocity and high momentum) to the wall (no velocity and no momentum).

\section{Microscopic Description}

Fluid in laminar flow moves as a result of an overall pressure drop causing a velocity profile to develop (no velocity at the wall, maximum velocity at the pipe centerline). Therefore, at each pipe radius, layers of fluid flow past each other at different velocities. Faster flowing layers tend to speed up slower layers along resulting in momentum transfer from faster layers in the middle of the pipe to slower layers closer to the pipe walls.

\section{Molecular Description}

Fluid molecules are moving in random Brownian motion until a pressure is applied at the pipe inlet causing the formation of a velocity gradient from centerline to pipe wall. Once the gradient is established, molecules that randomly migrate from an area of high momentum to low momentum will take along the momentum they possess and will transfer some of it to other molecules as they collide (increasing the momentum of the slower molecules). Molecules that randomly migrate from low to high momentum will absorb some momentum during collisions. As long as the overall velocity gradient is maintained, the net result is that momentum is transferred by molecular motion from areas of high momentum to areas of low momentum and ultimately to thermal dissipation at the pipe wall.

\section{Mixed Description}

Students use more than one model in their description.

Table 3. Number of causal descriptions used by students

\begin{tabular}{|l|c|}
\hline $\begin{array}{l}\text { Number of instances of causal } \\
\text { properties used in student descriptions }\end{array}$ & Number of students \\
\hline No causal descriptions & 4 \\
\hline 1 causal description & 9 \\
\hline 2 causal descriptions & 72 \\
\hline 3 causal descriptions & 3 \\
\hline 4 causal descriptions & 1 \\
\hline 5 causal descriptions & 1 \\
\hline 6 causal descriptions & 2 \\
\hline Non-responsive & \\
\hline
\end{tabular}


Table 4. Types of descriptions used by students

\begin{tabular}{|l|c|}
\hline \multicolumn{1}{|c|}{ Description type used in response } & Number of students \\
\hline Macroscopic & 4 \\
\hline Microscopic & 10 \\
\hline Molecular & 6 \\
\hline Mixed & 14 \\
\hline Non-responsive & 5 \\
\hline
\end{tabular}

\section{Discussion}

Overall, 33 of 37 students included at least one instance of causal language in their description of this phenomenon and 28 of 34 score-able responses used macroscopic, microscopic or mixed models. Clearly, these students do NOT use molecular mental models to describe molecular processes such as viscous momentum transfer. For example, one student used a macroscopic view to describe the process as:

"overcoming certain forces that are causing it [fluid] to stay in one place. One of these forces is the viscous force."

Another student used a microscopic view to describe the process as:

"fluid particles in one layer tending to 'grab hold' of fluid particles in the next layer so that some momentum is transferred from one layer to the next."

Several students invoked the idea that momentum is a substance (another common misconception characteristic); one described the process as:

"molecules in the fluid trying to flow past one another and thereby momentum is transferred between these molecules."

Only six of the students used some flavor of molecular behavior in their description of the process with statements like this one:

"Each molecule in the fluid has kinetic energy and momentum with some magnitude and direction. A portion of this energy and momentum is transferred between molecules when they collide. There is a net or average direction and magnitude which then causes a net transfer of kinetic energy and momentum." 
The results from our preliminary study suggest that senior-level chemical engineering students do not tend to think of viscous momentum transport as fundamentally a molecular-level process even though they have been exposed to concepts of molecules and molecular dynamics in at least 8-10 courses in their curriculum. At this point, we cannot separate the effects of some textbooks and instructional materials that invoke only macroscopic and microscopic descriptions of viscous action from fundamental causal misconceptions which students may form prior to beginning formal engineering education. Given the findings in this work, we must also pose the following question:

At what level (macroscopic, microscopic, molecular) do undergraduate engineering students need to understand phenomena which are fundamentally emergent and molecular in nature?

This is a question for on-going discussion within the engineering education community.

\section{References}

1) Reiner, M., Slotta, J.D., Chi, M.T.H., and Resnick, L.B., "Naive Physics Reasoning: A Commitment to Substance-Based Conceptions," Cognition and Instruction, 18(1), 1-34, 2000.

2) Garnett, P.J., and Hackling, M., "Students' Alternative Conceptions of Chemistry: A Review of Research and Implications for Teaching and Learning," Studies in Science Education, 25, 69, 1995.

3) Chi, M.T.H., "Cognitive Understanding Levels," in Encyclopedia of Psychology, American Psychological Association and Oxford University Press, in press.

4) Chinn, C. A., and Brewster, W. F., "The Role of Anomalous Data in Knowledge Acquisition: A Theoretical Framework and Implications for Science Instruction," Review of Educational Research, 63, 1-49, 1993.

5) Piaget, J., The Grasp of Consciousness, Routhledge and Kegan Paul, London, 1977.

6) Chi, M.T.H., "Misunderstanding Emergent Processes as Causal," submitted for publication. Advance copy available at www.pitt.edu/ chi.

7) Ferrari, M. and Chi, M.T.H, “The Nature of Naïve Explanations of Natural Selection,” International Journal of Science Education, 20, 1231-1256, 1998.

8) Marek, E.A., Cowen, C.C., and Cavallo, A.M.L., "Student's Misconceptions about Diffusion: How Can They be Eliminated?", The American Biology Teacher, 567, 74-77, 1986.

9) Hestenes, D., Wells, M. and Swackhamer, G., "Force Concept Inventory," The Physics Teacher, 30, 159-166, 1992.

10) Chi, M.T.H, and R.D. Roscoe, "The Processes and Challenges of Conceptual Change," to appear in Reframing the Process of Conceptual Change: Integrating Theory and Practice, Limon, M. and Mason, L., eds., Kluwer Academic Publishers, The Netherlands.

\section{Biographical Information}

RONALD L. MILLER is Professor of Chemical Engineering and Petroleum Refining at the Colorado School of Mines where he has taught chemical engineering and interdisciplinary courses and conducted research in educational methods for over seventeen years. He has received three university-wide teaching awards and has held a Jenni teaching fellowship at CSM. His paper entitled "Connections: A Longitudinal Study of an Integrated Freshman Program" (co-authored with Barbara Olds) won the award for best paper in the Educational and Research Methods Division of ASEE during the 2001 annual conference. He has received grant awards for educational 
research from the National Science Foundation, the U.S. Department of Education, the National Endowment for the Humanities, and the Colorado Commission on Higher Education.

RUTH A. STREVELER is the Director of the Center for Engineering Education and the Director of Academic Services at the Colorado School of Mines. Dr. Streveler received her Ph.D. in Educational Psychology from the University of Hawaii at Manoa. She also holds a Master of Science in Zoology from the Ohio State University and a Bachelor of Arts in Biology from Indiana University at Bloomington. She is co-director of an NSF-sponsored project to develop assessment instruments for identifying misconceptions in engineering students. Her paper entitled "Investigating Student Misconceptions in the Design Process Using Multidimensional Scaling," was a finalist for the Educational and Research Methods Division best paper award for the 2001 ASEE national conference.

BARBARA M. OLDS is Associate Vice President for Academic Affairs and Professor of Liberal Arts and International Studies at the Colorado School of Mines where she has been a member of the faculty for the past eighteen years. Dr. Olds has received the Brown Innovative Teaching Grant and Amoco Outstanding Teaching Award at CSM and was the CSM Faculty Senate Distinguished Lecturer for 1993-94. She also received the Helen Plants Award for Best Workshop at the 1992 Frontiers in Education national conference and was awarded a Fulbright fellowship to teach and conduct research in Sweden during the 1998-99 academic year. She has received grant awards from NSF, FIPSE, NEH, and the Colorado Commission on Higher Education. 